patients on SLGT2 inhibitor. Average HbA1c, T2DM patients $=62.7 \mathrm{mmol} / \mathrm{mol}$. HFrEF medication 3 classes: Beta Blockers/ Angiotensin-converting-enzyme inhibitors, Angiotensin II Receptor Blockers or Sacubitril Valsartan/ Mineralocorticoid receptor antagonists. No therapy, 2 (0.62\%), Monotherapy: 22 (6.85\%), Dual-therapy 156 (48.60\%), Triple-therapy 141 (43.93\%).

Conclusion Applying DAPA HF inclusion criteria, 292 $(90.97 \%)$ should be considered for introduction of SGLT2 inhibitors. Renal function isn't a significant barrier to SGLT2 inhibitor introduction. SGLT2 inhibitors aren't widely prescribed in patients with T2DM and HFrEF. Following recent NICE approval, there is scope for local and regional guidelines, directed at primary and secondary care for the prescribing of SLGT2 inhibitors in a HFrEF population.

Conflict of Interest Nil

\section{NHS TEST BED PROJECT: MONITORING OF HEART FAILURE PATIENTS IN THE COVID-19 PANDEMIC}

${ }^{1}$ Kajaluxy Ananthan, ${ }^{2}$ Sadia Khan, ${ }^{2}$ Chelsea and Westminster NHS Test Bed project group. ${ }^{1}$ North West London Deanery, South Wimbledon, UK; ${ }^{2}$ Chelsea and Westminster NHS Foundation Trust

\subsection{6/heartjnl-2021-BCS.143}

Introduction Heart failure carries a high morbidity and mortality but increasing numbers of patients are diagnosed with heart failure, with prevalence currently estimated as 26 million worldwide. ${ }^{1}$ This better recognition of the syndrome is also compounded by the increased number of readmissions for heart failure, which carries an increased mortality risk for heart failure patients. ${ }^{2}$ We evaluated: the use of NHS digital model for ambulation of heart failure patients called the NHS Test Bed project and the use of digital cardiology to follow up patients to detect early signs of deterioration, and hence prevent readmission. Its importance is recognised increasingly in the global COVID-19 pandemic to help free up inpatient beds.

Methods We initially evaluated the time involved in providing an ambulatory heart failure service compared to an inpatient admission for decompensation of heart failure. The NHS Test Bed project is a method of providing access to ambulatory services for heart failure patients and we evaluated the impact of this on admissions, focusing on Emergency Department presentations and emergency inpatient admissions.

Results We have demonstrated that an ambulatory heart failure service leads to a reduction in time caring for each patient by 4 hours and 6 minutes compared to an inpatient admission (tables $1 \& 2$ ). Our NHS Test Bed study was conducted over a two-year timeframe (inclusive of the introduction of the Combined Application System Innovation (CASI) tool to access ambulatory care services in April 2019) shows a promising linear trend with a step-by-step reduction in Emergency Department presentations for heart failure patients every month (figure 1). However, this was not statistically significant as a greater reduction was seen in the control group who did not have access to this service. The largest study of 1600 heart failure patients used telephone-based heart failure monitoring. ${ }^{3}$ This showed no reduction in mortality or hospitalisations attributed to this monitoring strategy, but this was attributed to poor adherence with only 55\% of patients taking part by the six-month timepoint. The deficit in our study and others

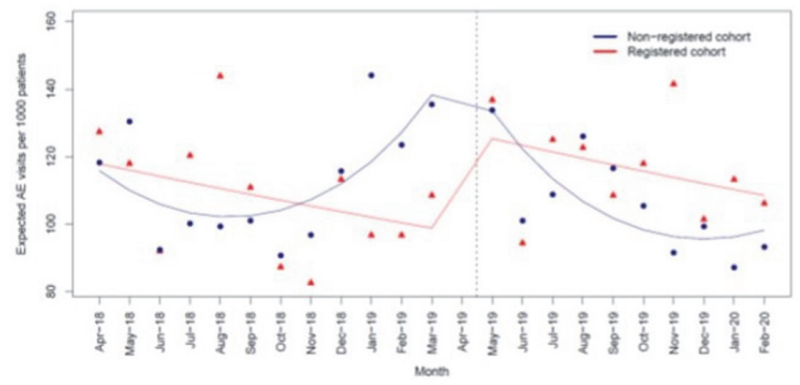

Abstract 146 Figure 1 Representation of the NHS Test Bed data showing the effects of registering for the Combined Application System Innovation tool to access ambulatory care services (red) versus not

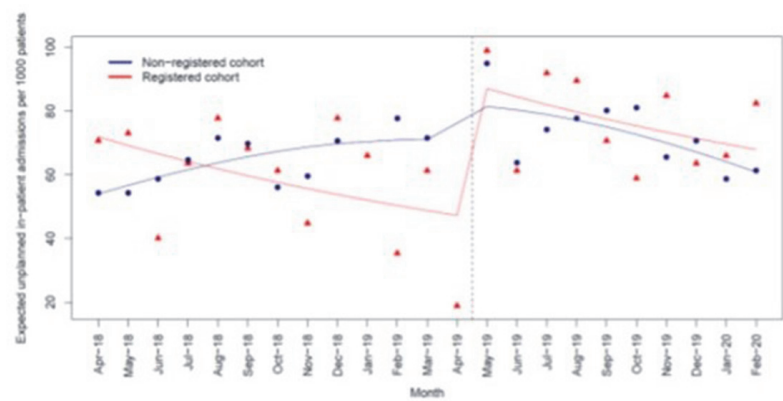

Abstract 146 Figure 2 Representation of the NHS Test Bed data showing the effects of registering for the Combined Application System Innovation tool to access ambulatory care services fred) versus not registering (blue) on the number of emergency hospital admissions for every 1,000 patients. Lines represent the Poisson regression model fit for the 2 cohorts

Abstract 146 Table 1 Journey of a paUent admitted to hospital for heart $f$ ailuie decompensation in terms of hours of staff time spent looking after them

\begin{tabular}{|c|c|}
\hline One off events & \\
\hline Bookedin & 5 mirutes \\
\hline See in in $I+E+B$ OOODS & 20 minutes \\
\hline Chest $x-r a y+$ porters & 25 minutes \\
\hline STET furesemide & 10 minutes \\
\hline Transfer to XXV & 15 minutes \\
\hline $\begin{array}{l}\text { Clerking by medical team and } \\
\text { drags written ap, post take }\end{array}$ & 1 hour \\
\hline $\begin{array}{l}\text { Paxmaty medicine } \\
\text { reconcilintion }\end{array}$ & 20 minates \\
\hline Referral to cardis & 15 minutes \\
\hline Scen by cardio & 30 minates \\
\hline Seea by heart failure team & 30 minutes \\
\hline \multirow[t]{2}{*}{ Discharge summary } & 15 minutes \\
\hline & 4 hrs 10 minutes \\
\hline \multicolumn{2}{|l|}{ Daily ewents } \\
\hline Furosemide infusion & 15 minutea/day \\
\hline Daily ward rounds & 10 minutes/ day \\
\hline Dxily bloods & 5 minutes/day \\
\hline Welghts and fruid restricting & 10 minutes/day \\
\hline \multirow[t]{2}{*}{ Obs 4 bounly } & 12 minutes/day \\
\hline & $\begin{array}{l}58 \text { minutes } \times 3=156 \\
\text { Multiplied by } 3 \text { as average patient stars } \\
\text { for } 3 \text { sars as per data since lanuary } 2019\end{array}$ \\
\hline Total time & $6 \mathrm{hrs} 46$ minutes \\
\hline
\end{tabular}


Abstract 146 Table 2 Journey of a patient seen in Ambulatory Care in terms of hours of staff time spent looking after them

\begin{tabular}{|l|l|}
\hline Each vat & \\
\hline Booked in & 5 minutes \\
\hline See a by Doctor and bloods taken & 20 minutes \\
\hline Furonemide infulion & 2 hours \\
\hline Dischaze summary & 15 minutes \\
\hline Total time & 2 hours 40minutes \\
\hline
\end{tabular}

in demonstrating a real-world benefit could be attributed to small numbers of patients and short timeframes to evaluate impact.

The results also help convey an important safety aspect of using the CASI tool showing a 1.9-fold (95\% CI: 1.25 2.89 ; $\mathrm{p}$-value $=0.007$ ) increase in the number of emergency admissions for heart failure compared to prior to induction of CASI in the registered users (figure 2). This demonstrates an important triage system embedded in the NHS test bed work in being able to not just send patients to ambulatory care but also filter out patients that need more urgent review.

Conclusion It is important to appreciate the importance of an ambulatory heart failure service in freeing up NHS beds. Evaluating the NHS Test Bed project over a longer timeframe with large numbers of patients to reach statistical significance will be of vital importance to prepare for the future surges of the COVID-19 pandemic.

Conflict of Interest None

\section{REFERENCES}

1. Ponikowski $\mathrm{P}$, Anker SD, AlHabib KF, Cowie MR, Force $T L$, Hu $S$, Jaarsma $T$, Krum $H$, Rastogi V, Rohde LE, et al. Heart failure: Preventing disease and death worldwide. ESC Heart Fail 2014;1:4-25. doi: 10.1002/ehf2.12005.

2. Buddeke J, Valstar GB, van Dis I, et al. Mortality after hospital admission for heart failure: improvement over time, equally strong in women as in men. BMC Public Health 2020;20:36. https://doi.org/10.1186/s12889-019-7934-3

3. Koehler $F$, Koehler $K$, Deckwart 0 , et al. Efficacy of telemedical interventional management in patients with heart failure (TIM-HF2): a randomised, controlled, parallel-group, unmasked trial. Lancet 2018;392:1047-57.doi:10.1016/501406736(18)31880-4 pmid:http://www.ncbi.nlm.nih.gov/pubmed/30153985

\section{DAILY WEIGHT AND FLUID BALANCE ASSESSMENT IN PATIENTS ADMITTED WITH ACUTE HEART FAILURE}

Norildin Al-Refaie, Louis Taylor. Oxford University Hospitals NHS Trust, Oxford, UK

\subsection{6/heartjnl-2021-BCS.144}

Introduction Associated with high morbidity and mortality, congestive heart failure $(\mathrm{CHF})$ is a common consequence of numerous cardiac diseases.Close monitoring of fluid balance and daily weights in patients admitted with acute heart failure (AHF) plays a crucial role in its management and allows the therapeutic efficacy of diuretic therapy to be maximized. It's recommended by ESC guidelines that patients hospitalized due to acute heart failure should be weighed daily and have an accurate fluid balance chart completed.

Purpose To collect information on the demographic of the patients admitted, type of heart failure and underlying cause. To measure the compliance for daily weight and fluid balance assessment in patients admitted with AHF and receiving IV diuretic therapy.
Method Retrospective analysis of data on 94 patients who were admitted over 6 months period to the cardiology ward of a district general hospital with $\mathrm{AHF}$ and requiring intravenous diuretic therapy.

Results Average age for admissions was 76.5 year old (54\% male, $46 \%$ female), and average length of admission was 4.9 days. Table 1 shows the number of patients of Heart failure with reduced ejection fraction (HFrEF) or Heart failure with

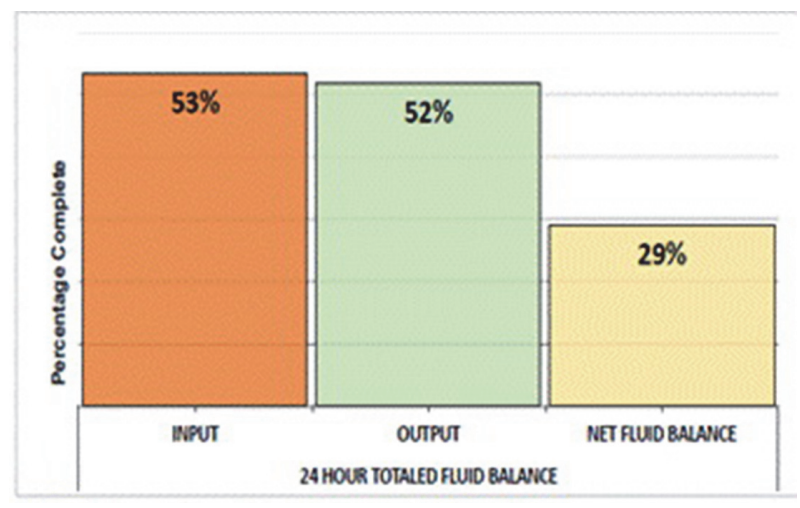

Abstract 147 Figure 1 Completion of fluid balance charts $(N=69)$

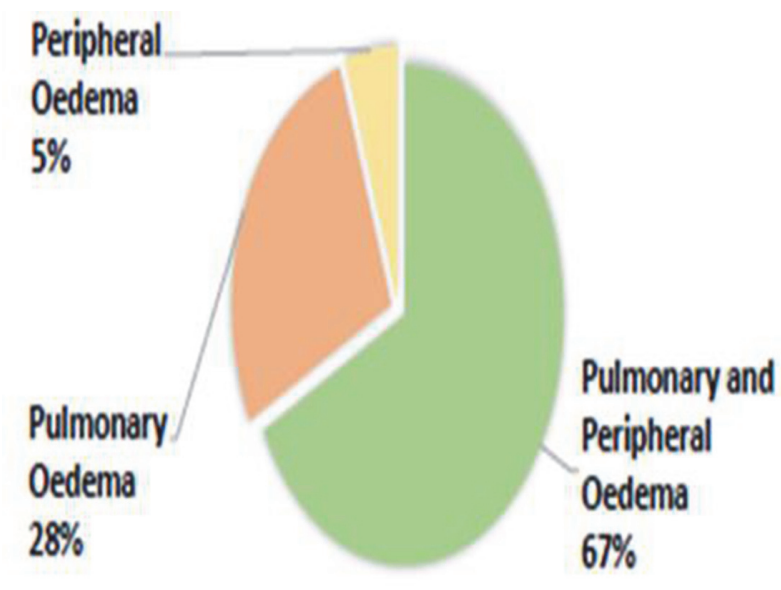

Abstract 147 Figure 2

\begin{tabular}{|c|c|c|}
\hline & HFrEF or HFmrEF & HFpEF \\
\hline Ischaemic heart disease & ${ }_{17}(29 \%)$ & $5(6 \%)$ \\
\hline Atrial fibrillation & $8(9 \%)$ & $11(13 \%)$ \\
\hline Other arrhythmia & o & $1(1 \%)$ \\
\hline Aortic valve disease & $5(6 \%)$ & ${ }_{5}(6 \%)$ \\
\hline Mitral valve disease & $2(2 \%)$ & $1(1 \%)$ \\
\hline Mixed valve disease & $2(2 \%)$ & $1(1 \%)$ \\
\hline Dilated cardiomyopathy & $10(11 \%)$ & o \\
\hline $\begin{array}{l}\text { Hypertrophic obstructive } \\
\text { Cardiomyopathy }\end{array}$ & o & $1(1 \%)$ \\
\hline Non-compaction cardiomyopathy & $1(1 \%)$ & 0 \\
\hline No clear cause & $13(15 \%)$ & $11(13 \%)$ \\
\hline Total & $58(67 \%)$ & $29(33 \%)$ \\
\hline
\end{tabular}

